\title{
Characterization of the Black Shank Pathogen, Phytophthora nicotianae, Across North Carolina Tobacco Production Areas
}

Courtney A. Gallup, Dow AgroSciences LLC, Indianapolis, IN 46268; Kestrel L. McCorkle, Department of Entomology and Plant Pathology, North Carolina State University, Raleigh 27695; Kelly L. Ivors, Department of Horticulture and Crop Science, California Polytechnic State University, San Luis Obispo, CA 93407; and David Shew, ${ }^{\dagger}$ Department of Entomology and Plant Pathology, North Carolina State University

\begin{abstract}
Black shank disease of tobacco, caused by the oomycete Phytophthora nicotianae, is a major threat to production in the United States and tobacco-producing areas worldwide. In a statewide survey of North Carolina, the rapid shift from race 0 to race 1 was documented. Collected pathogen isolates were characterized phenotypically for mating type and mefenoxam sensitivity, and genotypically by comparing sequences from three cytoplasmic and two nuclear regions. Both the A1 and A2 mating types were found throughout the state. When both mating types were recovered from the same field, pairings of isolates yielded viable oospores, indicating for the first time the potential for sexual sporulation

by $P$. nicotianae in natural populations. Because the loss of complete resistance required a renewed use of the fungicide mefenoxam, a subset of the survey isolates was screened for sensitivity to the fungicide. All isolates were sensitive, with a mean effective concentration to inhibit $50 \%$ of hyphal growth of $0.4 \mu \mathrm{g} / \mathrm{ml}$ that was similar across mating types and races. Molecular characterization of 226 isolates revealed that the pathogen exists as multiple clonal types within the state. Genetic diversity among the pathogen population and the potential for sexual recombination may help explain the ability of the pathogen to rapidly adapt to host resistance genes.
\end{abstract}

Black shank of tobacco, caused by the soilborne pathogen Phytophthora nicotianae, occurs in most tobacco production areas (Gallup et al. 2006; Shew and Lucas 1991). Infection can occur in the roots, stems, and leaves, and leads to root and stem necrosis, wilting, chlorosis, disking of the pith, and death (Gallup et al. 2006; Lucas 1975). In North Carolina, black shank causes high losses in crop value each year that can exceed \$30 million (Mila and Radcliff 2015). Disease management relies upon an integration of practices, including crop rotation, planting resistant varieties, and fungicide applications (Mila and Radcliff 2015; Shew and Lucas 1991). Management strategies, in addition to environmental conditions, place selection pressure on the pathogen population that can lead to observed shifts in phenotypic and genotypic traits. In tobacco populations of $P$. nicotianae, a few studies have phenotypically characterized the pathogen population (Csinos and Bertrand 1994; Gallup and Shew 2010; Parkunan et al. 2010). Studies of genotypic characterization have either focused on small populations in the same field (Sullivan et al. 2010), a genomewide comparison of a representative isolate of race 0 and race 1 from tobacco (Liu et al. 2016), or global populations from many hosts in addition to tobacco (Mammella et al. 2011, 2013). The lack of characterization of North Carolina isolates prompted our investigation.

Historically, P. nicotianae populations have been typed for phenotypic traits, including race, mating type, and mefenoxam sensitivity. In the United States, races 0,1 , and 3 have been reported, but race 0 and race 1 represent a majority of collected isolates (Gallup and Shew 2010). In the mid-1990s, there was a rapid race shift from the wild type (race 0 ) to race 1 of $P$. nicotianae after the introduction of complete resistance in agronomically acceptable tobacco varieties.

${ }^{\dagger}$ Corresponding author: D. Shew; E-mail: shew@ncsu.edu

Funding: This research was supported by grants from the North Carolina Tobacco Research Commission, the North Carolina Tobacco Foundation, Inc., and the Tobacco Trust Fund of North Carolina.

*The $\boldsymbol{e}$-Xtra logo stands for "electronic extra" and indicates that two supplementary tables are published online.

Accepted for publication 13 December 2017.

C) 2018 The American Phytopathological Society
Complete resistance to race 0 is conferred by either the $P h p$ and $P h l$ genes, which were incorporated into flue-cured tobacco from Nicotiana plumbaginifolia and into burley tobacco from $N$. longiflora, respectively (Chaplin 1962; Johnson et al. 2002; Valleau et al. 1960). The widespread occurrence of race 1 in North Carolina greatly impacts management strategies because race 1 isolates overcome all available complete-resistance genes. Race 3 overcomes only the $P h l$ source of single-gene resistance and is managed by the same practices as race 0 and race 1 (Gallup and Shew 2010; Gallup et al. 2006). In North Carolina, all three races of the pathogen (Gallup and Shew 2010) and both mating types have been reported (Lucas 1975).

P. nicotianae is heterothallic, requiring two mating types, A1 and A2, for the production of oospores (Tsao et al. 1980). Sexual reproduction has been documented and investigated in several in vitro studies with P. nicotianae (Chern and Ko 1994; Jee and Ko 1997; Jee et al. 2002) but it has not been demonstrated in natural agroecosystems. To date, production of oospores has been considered nonexistent or unimportant in the epidemiology of the pathogen on tobacco but it has not been thoroughly explored (Panabières et al. 2016). If isolates of both mating types are in the same location, and they are capable of producing viable oospores, this would increase the pathogen's evolutionary potential to quickly adapt to changes in management strategies such as host resistance and fungicide applications. Mefenoxam is one of the primary fungicides used for black shank control (Mila and Radcliff 2015) and is recommended with applications of fungicides with other modes of action such as fluopicolide and oxathiapiproline (Bittner and Mila 2016). Resistance to mefenoxam has not been reported in tobacco populations of $P$. nicotianae but has been documented on multiple ornamental hosts and in citrus (Hu et al. 2008; Hwang and Benson 2005). Since the failure of singlegene resistance, many growers have had to rely more heavily on chemical controls to manage black shank.

Genotypic characterization, in addition to phenotypic characterization, of the tobacco population of $P$. nicotianae will increase our knowledge of how host resistance, fungicide applications, and other management practices affect population structure and future disease control strategies. Genetic variation in populations of $P$. nicotianae has been determined using restriction fragment length polymorphism (RFLP), random amplified polymorphic DNA (RAPD), amplified fragment length polymorphisms (AFLP), microsatellites 
(simple-sequence repeats), and mitochondrial DNA (mtDNA) and nuclear DNA genes to examine population biology (Biasi et al. 2015, 2016; Blaya et al. 2015; Gallup 2009; Lacourt et al. 1994; Mammella et al. 2011, 2013; Sullivan et al. 2010; Zhang et al. 2003). RFLP, RAPD, and AFLP markers have been used widely in past years because genetic information of the organism is not needed to develop markers. However, these types of markers are inferior to other molecular methods used for intraspecies genetic variability because they can be expensive and difficult to reproduce in other labs (Grünwald and Goss 2011). Single-nucleotide polymorphisms (SNP) are ideal for intraspecific variability studies because most are biallelic and many are spread throughout the genome (Brumfield et al. 2003). In a study by Mammella et al. (2013), the population structure of a global population of $P$. nicotianae was inferred from SNP in four mitochondrial and three nuclear DNA sequences. SNP were found in both types of DNA sequences. Out of 96 isolates from citrus, ornamental, and tobacco hosts, there were 50 haplotypes based on SNP in mtDNA sequences. A few studies have been done to elucidate the population genetic structure of $P$. nicotianae for various hosts across the world but none have focused on $P$. nicotianae populations from tobacco (Blaya et al. 2015; Lacourt et al. 1994; Mammella et al. 2011, 2013; Zhang et al. 2003).

The objectives of our study were to genetically characterize the $P$. nicotianae population in North Carolina to determine population structure and possible correlation of haplotypes to phenotypic traits, including race, mating type, and mefenoxam sensitivity. In addition, we wanted to determine whether sexual recombination in the field could occur and result in viable oospores that could contribute to genetic variability.

\section{Materials and Methods}

Isolate recovery. Isolates were obtained from soil samples taken from tobacco fields where plants had characteristic symptoms of black shank disease. Isolates were collected from soil samples so that the isolates best represented the pathogen population present in the field regardless of resistance genes present in planted tobacco varieties. In summer 2006, soil was collected from 76 tobacco fields in 23 North Carolina counties, representing the major flue-cured and burley tobacco-producing regions of the state. Fields were selected based on occurrence of the disease in summer 2006 and previous years. Using a $3-\mathrm{cm}$ soil probe, two to four soil cores were collected 15 to $20 \mathrm{~cm}$ deep and 5 to $8 \mathrm{~cm}$ from the stem of tobacco plants displaying typical black shank symptoms. At least 10 plants were sampled from each field. The soil probe was rinsed with $70 \%$ ethanol or $0.5 \% \mathrm{NaClO}$ between fields and allowed to dry. Samples were stored in a dry, dark location until ready to assay.

Soil assays were conducted according to Sullivan et al. (2005a), with some modifications, in order to collect individual $P$. nicotianae isolates from the soil around each plant. Briefly, three 1-g subsamples were each suspended in $25 \mathrm{ml}$ of deionized (DI) water and distributed over five dishes of PARPH V8 semiselective medium. The PARPH medium contained 5\% clarified V8 juice as the basal medium and was amended with pentachloronitrobenzene, hymexazol, ampicillin, rifampcin, and pimiricin (Kannwischer and Mitchell 1978; Shew 1983). The dishes were incubated at room temperature for $48 \mathrm{~h}$; then, the soil was washed from the agar surface. If present, individual colonies were immediately transferred to fresh PARPH. To ensure a pure culture of the isolate, small pieces of hyphal tissue were taken from the edges of colonies and transferred to a PARPH medium two consecutive times using the same technique. If no colonies were visible, the dishes were allowed to incubate for an additional $24 \mathrm{~h}$. If no colonies were present following $72 \mathrm{~h}$, the procedure was repeated using $1.5 \mathrm{~g}$ of soil per subsample. If no isolates were recovered from the second soil assay, the soil sample was mixed with sterile greenhouse soil and placed in a 10-cm-diameter clay pot and a 4-week-old susceptible tobacco seedling, cultivar Hicks, was planted into the soil. Tobacco seedlings were grown at temperatures of 30 and $26^{\circ} \mathrm{C}$, day and night, respectively, under a 14-h period of light. Plants were fertilized once weekly with 10-10-10 Miracle-GRO (Scotts Miracle-Gro Company, Marysville, $\mathrm{OH}$ ) until black shank symptoms developed. When a plant developed typical black shank symptoms, a $P$. nicotianae isolate was obtained from the symptomatic stem tissue. Stem tissue was rinsed in $0.5 \% \mathrm{NaClO}$ for $30 \mathrm{~s}$, rinsed in sterile DI water for $30 \mathrm{~s}$, blotted on a clean paper towel, then placed on the surface of semiselective PARPH medium.

Isolates were successively transferred to PARPH until free of contaminants. Pure cultures were maintained on 5\% clarified carrot agar (CA) (Sullivan et al. 2005b) until ready for race, mating type, or fungicide sensitivity screenings. All screenings for race, mating type, and fungicide sensitivity were completed within a year of collection. Isolates were kept free of contaminants by transferring to fresh CA once every 2 weeks. Whenever possible, 1 isolate was collected from each soil sample, resulting in at least 10 isolates from each field of the 76 infested fields. Confirmation of isolate identity was done using morphological characteristics, and 266 of the 581 collected isolates had multiple genes sequenced. Sequencing of the internal transcribed spacer (ITS) gene region was done using primers and methods described by White et al. (1990); then, sequences were blasted on the National Center for Biotechnology Information to confirm species identity.

Race determination. The race of each isolate was identified according to Sullivan et al. (2005b), with some modifications. Briefly, three 4-week-old seedlings of each differential cultivar-Hicks (susceptible), NC $1071(P h p)$, and KY 14xL8 (Phl) - were transplanted into cell packs ( 4 by 4 by $5 \mathrm{~cm}$ ) containing a 1:1:1 volume mixture of steam-pasteurized soil, Metro mix 200 growing medium (Sun Gro Horticulture, Agawam, MA), and coarse builder's sand. Plants were grown using the same conditions as seedlings to bait for $P$. nicotianae isolates. Inoculum of each isolate was prepared by placing sterile oat grains onto a 3- to 7-day-old CA culture. Sterile oat grains were prepared by autoclaving $500 \mathrm{~cm}^{2}$ of oat with $300 \mathrm{ml}$ of DI water for three consecutive days. The pathogen colonized the oat grains during a 7 to 10 -day incubation period at $28^{\circ} \mathrm{C}$. Plants were inoculated 1 week after transplant with oat grains colonized by a single pathogen isolate. Two colonized oat grains were placed into 2-cm-deep holes in each cell ( 4 by 4 by $5 \mathrm{~cm}$ ), one on either side of the seedling stem. After 14 days, plants were scored for the presence or absence of symptoms. Isolates that only caused symptoms on susceptible Hicks were designated as race 0 . If all differential cultivars were symptomatic, then the isolate was scored as race 1. If Hicks and at least one KY 14xL8 seedling were symptomatic and no NC 1071 seedlings developed symptoms, then the isolate was scored as race 3 .

Mating type survey and isolate compatibility. The mating type of each isolate was identified by pairing each isolate with two separate A1 and A2 tester isolates of $P$. nicotianae on CA amended with water-soluble cholesterol (CAS) (Sigma-Aldrich, St. Louis) at a concentration of $5 \mu \mathrm{g} / \mathrm{ml}$. The cholesterol suspension was filter sterilized directly into the medium using a $0.2-\mu \mathrm{m}$ syringe filter (NALGENE, NUNC; Thermo Scientific, Rochester, NY). Pairings were conducted by placing a 1-cm-diameter colonized agar plug of an isolate on one side of each of two Petri dishes containing CAS. A similar colonized plug of the A1 tester was placed on the opposite side of one Petri dish, and a plug of the A2 tester was placed on the opposite side of the other dish, so that plugs were $6 \mathrm{~cm}$ apart. The Petri dishes were wrapped in Parafilm, incubated in the dark at $24^{\circ} \mathrm{C}$ for 4 weeks, then manually observed for the presence of oospores using an inverted compound microscope. If oospores formed when an isolate was paired with the A1 tester, then the isolate was considered A2, and vice versa. If oospores formed with both testers, then the isolate was designated as A1/A2. However, if no oospores were found, then the isolate was paired again using a different set of $\mathrm{A} 1$ and $\mathrm{A} 2$ testers. If oospores still did not form, then the isolate was designated as A0. Pairings were repeated twice for each isolate to confirm mating type. Distribution of mating type for each field was examined and, if the distribution was mixed, then isolates from within a field were paired to determine whether the two mating types would produce viable progeny. If oospores formed, then pairings were evaluated for percent oospore viability by pairing isolates to each other in five $6-\mathrm{cm}$ Petri dishes containing CAS with a reduced concentration of Bacto agar at $3 \mathrm{~g} /$ liter. Plates were incubated in the dark for 4 weeks at 
$25^{\circ} \mathrm{C}$; then, oospores were extracted and stained according to Sutherland and Cohen (1983), with some modifications.

To extract oospores from agar, the entire contents of the five dishes were placed into a sterile blender cylinder containing $10 \mathrm{ml}$ of sterile DI water and blended until smooth. The suspension was pipetted $1 \mathrm{ml}$ at a time into $1.7-\mathrm{ml}$ microcentrifuge tubes. The tubes were centrifuged for $5 \mathrm{~min}$ at $10,000 \mathrm{rpm}$ and the supernatant was discarded. Sterile DI water $(0.5 \mathrm{ml})$ was added to each tube, vortexed, and centrifuged at 12,000 rpm for $6 \mathrm{~min}$, and the supernatant was discarded again. The wash process was repeated five times.

To determine viability, oospores were stained with thiazolyl blue tetrazolium bromide (MTT) (Sigma-Aldrich) (Sutherland and Cohen 1983). For this, $0.5 \mathrm{ml}$ of MTT was added to each tube, vortexed, then incubated in the dark at $35^{\circ} \mathrm{C}$ for $48 \mathrm{~h}$. A droplet of the suspension was placed on a slide with a coverslip and examined at $\times 40$ to $\times 100$. The first 100 oospores found were assessed for viability, using multiple slides if necessary. Viable oospores were red to purple in color, while spores that were black or unstained were considered nonviable.

Mefenoxam sensitivity. A subset of 120 isolates that represented all counties, races, and mating types was screened for sensitivity to mefenoxam (Ridomil Gold SL, $45.3 \%$ active ingredient). A $1-\mathrm{cm}$ plug was taken from the growing margin of a 3-day-old culture of each isolate and placed in the center of Petri dishes containing $18 \mathrm{ml}$ of $5 \%$ CA amended with mefenoxam at $0,0.1,1$, or $10 \mu \mathrm{g} / \mathrm{ml}$. These concentrations bracketed the previously reported concentrations needed to define the effective concentration to inhibit $50 \%$ of hyphal growth $\left(\mathrm{EC}_{50}\right.$ values) for P. nicotianae (Shew 1984, 1985). Plates were incubated in the dark at $25^{\circ} \mathrm{C}$ for 7 days; then, the largest radius of mycelial growth was measured to the closest millimeter. Percent inhibition was calculated by taking the mean radius of the mycelial growth across all replications and dividing it by the average mycelial growth on nonamended medium. Treatments were replicated three times, and the experiment was conducted twice. Analysis of variance was performed on percent inhibition and $\mathrm{EC}_{50}$ values were determined using the PROC GLM procedure of SAS (version 9.1; SAS Institute, Cary, NC). Means separation was conducted using the Waller-Duncan K-ratio test $(k=100)$. If phenotypic data were missing for an isolate, such as race or mating type, then those isolates were excluded from the comparisons for which the data were missing.

Molecular characterization. A subset of 226 isolates collected from burley and flue-cured tobacco fields, representing all 23 counties and from fields with mixed mating types and races, was selected for molecular characterization. Isolates growing on $\mathrm{CA}$ were transferred to $5 \mathrm{ml}$ of pea broth (frozen peas at $120 \mathrm{~g} /$ liter of distilled $\mathrm{H}_{2} \mathrm{O}$ ) in 50-ml Falcon tubes (Fisher Scientific, Hampton, NH) and incubated at room temperature $\left(23\right.$ to $\left.25^{\circ} \mathrm{C}\right)$ for 7 to 10 days. Mycelium was removed and ground in microcentrifuge tubes using liquid nitrogen. Genomic DNA was isolated from $20 \mathrm{mg}$ of mycelium with the Puregene DNA isolation kit (Gentra Systems Inc., Minneapolis, MN) according to manufacturer protocols and eluted in $50 \mathrm{ml}$ of ultrapure water. DNA extracts were stored at $-20^{\circ} \mathrm{C}$. Universal oligonucleotide primers ITS4/ITS6 (White et al. 1990) were used to amplify the ITS ribosomal DNA (rDNA) region (ITS) and FM35/ FMPh10b were used to amplify portions of the $\operatorname{cox} 2+$ spacer gene region (cox2), following the reported protocols (Martin and Tooley 2003). Oligonucleotide primers ELONGF1/ELONGR1, TUBUF2/ TUBUR1, and NADHF1/NADHR1 reported by Kroon et al. (2004) and corresponding protocols were used to amplify the translation elongation factor $1 \alpha(E F-1 a), \beta$-tubulin $(\beta-t u b)$, and NADH dehydrogenase subunit 1 (nadh1) gene, respectfully. The same primers used for gene amplification were also used for sequencing for all genes except for cox2. Primer sets FM82/FM78 and FM79/FM80 were used to sequence cox2 after amplification using FM35/ FMphy 10b (Martin and Tooley 2003) (Table 1). Amplicon purification and sequencing was performed by the MCLAB sequencing facility in South San Francisco, CA (http://www.mclab.com). Sequences were visually edited and aligned using the multialignment program Sequencher (v.4.1.2; Gene Codes Corp., Ann Arbor, MI). Of the 226 isolates used for genetic characterization, 70 were sequenced for all five gene regions and 216 were sequenced for the $\operatorname{cox} 2$, nadhl, and ITS gene regions. Alignments were made for all amplified isolates for each gene region separately, both mitochondrial gene regions together, both nuclear gene regions together, and all gene regions concatenated together. Isolates with heterozygous ITS SNP were removed from the concatenated alignment to determine final number of haplotypes. Alignment matrices were uploaded to the public access website TreeBASE (https://treebase.org/).

\section{Results}

Isolate recovery. When possible, one isolate was recovered from each of at least 10 soil samples per field. However, soil samples were excluded from the study if no isolates were recovered after two soil assays and recovery with the bioassay was unsuccessful. Therefore, some fields were represented by fewer than 10 isolates. In total, 581 isolates were included in tests for race and mating type distribution.

Race determination. Of 581 isolates of $P$. nicotianae, 4 did not cause disease on any of the three cultivars (Hicks, NC 1071, and KY 14xL8) following two inoculation attempts and were excluded

Table 1. Target DNA gene regions, primers, primer sequences, and amplification conditions used for amplification and sequencing of the internal transcribed spacer (ITS), cox2 + spacer, NADH dehydrogenase subunit 1 (nadh1), translation elongation factor $1 \alpha$ (EF-1a), and $\beta$-tubulin gene regions for Phytophthora nicotianae isolates

\begin{tabular}{|c|c|c|c|}
\hline Target DNA & Primers $^{v}$ & Sequence $\left(5^{\prime}-3^{\prime}\right)^{w}$ & Amplification conditions \\
\hline \multirow[t]{2}{*}{ ITS } & ITS4 ${ }^{\mathrm{x}}$ & TCCTCCGCTTATTGATATGC & $\ldots$ \\
\hline & ITS6 $^{x}$ & GAAGGTGAAGTCGTAACAAGG & $56^{\circ} \mathrm{C}, 40 \mathrm{~s}$ \\
\hline \multirow[t]{6}{*}{$\operatorname{cox} 2+$ spacer } & FM35 & CAGAACCTTGGCAATTAGG & $\ldots$ \\
\hline & Fmphy-10by & GCAAAAGCACTAAAAATTAAATATAA & $\ldots$ \\
\hline & FM82y & (TTGGCAATTAGGTTTTCAAGATCC) & $\ldots$ \\
\hline & FM78y & (ACAAATTTCACTACATTGTCC) & $\ldots$ \\
\hline & FM79y & (GGACAATGTAGTGAAATTTGT) & $\ldots$ \\
\hline & FM80y & (AATATCTTTATGATTTGTTGAAA) & $58^{\circ} \mathrm{C}, 90 \mathrm{~s}$ \\
\hline \multirow[t]{2}{*}{ nadh1 } & NADHF1 ${ }^{z}$ & CTGTGGCTTATTTTACTTTAG & $\ldots$ \\
\hline & NADHR $1^{z}$ & CAGCAGTATACAAAAACCAAC & $56^{\circ} \mathrm{C}, 30 \mathrm{~s}$ \\
\hline \multirow[t]{2}{*}{$E F-1 a$} & ELONGF1 $^{\mathrm{z}}$ & TCACGATCGACATTGCCCTG & $\ldots$ \\
\hline & ELONGR $1^{z}$ & ACGGCTCGAGGATGACCATG & $60^{\circ} \mathrm{C}, 30 \mathrm{~s}$ \\
\hline \multirow[t]{2}{*}{$\beta-t u b$} & TUBUF $^{z}$ & CGGTAACAACTGGGCCAAGG & $\ldots$ \\
\hline & TUBUR $1^{z}$ & CCTGGTACTGCTGGTACTCAG & $60^{\circ} \mathrm{C}, 30 \mathrm{~s}$ \\
\hline
\end{tabular}

\footnotetext{
${ }^{\mathrm{v}}$ Primers used from other sources are indicated below.

${ }^{w}$ Primers in parentheses were used only for sequencing.

x White et al. 1990.

${ }^{y}$ Martin and Tooley 2003.

z Kroon et al. 2004.
} 
from further evaluation. All other isolates were pathogenic on one or more of the host differentials and were characterized as one of the three races described in North Carolina.

All previously reported races (races 0,1 , and 3 ) were found in the state, with $95 \%$ of all fields having race 1 present. Across the state, $75 \%$ of the isolates recovered were race $1,21 \%$ race 0 , and $4 \%$ race 3 (Table 2). The race structure between fields varied greatly. Only $4 \%$ of the fields had populations composed entirely of race $0 ; 20 \%$ had populations $>50 \%$ race $0 ; 20 \%$ had populations $>50 \%$ race 1 ; and $56 \%$ had populations consisting of only race 1 . Race 3 was identified in 14 of the 76 fields surveyed. This race was most frequently found in populations that were dominated by race 0 , with race 3 identified in only 5 fields that were predominantly race 1 (Supplementary Table S1). On average, the percentage of race 3 within a field was $30 \%$ in fields dominated by race 0 , compared with $12 \%$ in fields dominated by race 1 .

Mating type survey and isolate compatibility. Mating types were determined for isolates in 23,35 , and 17 tobacco fields in the mountains, piedmont, and coastal plains, respectively. Across all regions, $47 \%$ of the isolates were $\mathrm{A} 1,46 \%$ were $\mathrm{A} 2,1 \%$ was $\mathrm{A} 1 / \mathrm{A} 2$, and $6 \%$ of isolates were A0, with no oospores formed with any tester isolates. Mating type ratios differed by region, with a higher percentage of isolates with the A1 mating type found in the mountains and coastal plains and a higher percentage of isolates with an A2 mating type found in the piedmont. Of the fields sampled, the highest percentage of fields with mixed mating types was $61 \%$ in the mountains, followed by $41 \%$ of fields in the coastal plains, and $34 \%$ in the piedmont. At least one field in each tobacco-growing region had both mating types present and produced oospores when paired. Compatible isolates that formed oospores were recovered from 12 fields in the mountains, 11 fields in the piedmont, and a single field in the coastal plain. Five pairings were assessed for oospore viability, which varied depending on the isolate combination within the same field (Table 3 ). For example, within isolates from a Guilford County field (Piedmont region), isolate GC-11 yielded 20 and $48 \%$ viable oospores when paired with isolates GC-4 and GC-9, respectively. Pairings from fields in Surry County (Piedmont region) yielded between 44 and $48 \%$ viable oospores.

Table 2. Race structure of Phytophthora nicotianae in North Carolina tobacco regions

\begin{tabular}{lccc}
\hline & \multicolumn{3}{c}{ Proportion (\%)y } \\
\cline { 2 - 4 } Region $^{\mathbf{z}}$ & Race 0 & Race 1 & Race 3 \\
\hline Mountains (Western North Carolina) & 31 & 67 & 2 \\
Piedmont (Central North Carolina) & 7 & 90 & 3 \\
Coastal Plain (Eastern North Carolina) & 38 & 50 & 12 \\
Totals & 21 & 75 & 4 \\
\hline
\end{tabular}

y Races were determined by inoculating a set of host differentials: Hicks, susceptible; NC 1071, with the Php gene; and KY 14xL8, with the Phl gene.

${ }^{\mathrm{z}}$ Fields with active black shack disease were sampled from each geographic region of North Carolina. Isolates were obtained from soil collected from around symptomatic plants and a single isolate was obtained per plant. In total, 581 isolates were characterized in the study.

Table 3. Percentage of viable oospores from pairings of Phytophthora nicotianae isolates collected in North Carolina tobacco fields

\begin{tabular}{lllcc}
\hline County & Field $^{\mathbf{y}}$ & A1 isolate & A2 isolate & Oospore viability (\%) \\
\hline Guilford & $27-28$ & GC-11 & GC-9 & 48 \\
Guilford & $27-28$ & GC-11 & GC-4 & 20 \\
Guilford & $27-28$ & GC-15 & GC-2 & 26 \\
Surrey & 56 & SJ-7 & SJ-2 & 48 \\
Surrey & 53 & SC-1 & SC-2 & 44
\end{tabular}

${ }^{\mathrm{y}}$ Arbitrary field designation. Fields 27 and 28 share the same location but have different cropping histories.

${ }^{\mathrm{z}}$ Oospores formed were rated as viable based on a staining technique using tetrazolium bromide.
Mefenoxam sensitivity. Analysis of percent inhibition revealed no run effect $(P=0.5557)$; therefore, data from both runs of the experiment were combined for analysis. Mean percent inhibition increased logarithmically $(R=0.82)$ with increasing concentrations of mefenoxam (Table 4). The mean $\mathrm{EC}_{50}$ for all isolates was mefenoxam at $0.4 \mu \mathrm{g} / \mathrm{ml}$. The range of responses among isolates was great. For example, isolate 129 from Haywood County was inhibited by $85 \%$ at the lowest concentration and $100 \%$ at the highest concentration whereas other isolates, such as isolate 96 , had increased growth at the lowest concentration and was inhibited by $85 \%$ at the highest concentration. Individual responses varied most with mefenoxam at $0.1 \mu \mathrm{g} / \mathrm{ml}$, with $31 \%$ of the isolates having a larger growth radius than the fungicide-free control. However, growth at this concentration was sparse and generally weak.

The mean $\mathrm{EC}_{50}$ differed among counties (Supplementary Table $\mathrm{S} 2$ ). The most sensitive isolates were found in Stokes, Craven, Rockingham, and Alamance Counties, where the $\mathrm{EC}_{50}$ values were less than $0.0086 \mu \mathrm{g} / \mathrm{ml}$. The least sensitive isolates were found in Sampson and Watauga Counties, where the mean $\mathrm{EC}_{50}$ for mefenoxam ranged from 0.7621 to $0.7967 \mu \mathrm{g} / \mathrm{ml}$. Within a county, fields typically had statistically similar $\mathrm{EC}_{50}$ values $(P=0.2215$ to 0.9624$)$.

Sensitivity to mefenoxam was similar among the A1, A2, and A1/A2 mating types. The neutral mating type, A0, was more sensitive than the $\mathrm{A} 1$ and $\mathrm{A} 2$ mating types but not the A1/A2 type (Table 5). There were no differences in sensitivity to mefenoxam among races of $P$. nicotianae with mean $\mathrm{EC}_{50}$ values of mefenoxam at 0.3747 to $0.6388 \mu \mathrm{g} / \mathrm{ml}$ (Table 5).

Molecular characterization. High-quality ITS, $\operatorname{cox} 2$, and nadh1 sequences were obtained for 216 isolates and high-quality sequences of $\beta$-tub and $E F-1 a$ were obtained for 70 isolates. The ITS, $E F-1 a$, $\beta$-tub, nadh1, and cox 2 . contigs yielded sequences of 705,877 , 913, 794, and 902 bp in length, respectively. No SNP were identified in the $\beta-t u b$ and $E F-1 a$ gene regions for the population examined and nine SNP were collectively found in rDNA and mtDNA. Two SNP were found in ITS, five SNP in cox2, and two SNP in the nadh1 gene

Table 4. Percent growth inhibition of Phytophthora nicotianae in response to increasing mefenoxam concentrations

\begin{tabular}{lcc}
\hline & \multicolumn{2}{c}{ Inhibition $(\%)^{\mathbf{y}}$} \\
\cline { 2 - 3 } Mefenoxam $(\boldsymbol{\mu} \mathbf{g} / \mathbf{m l})^{\mathbf{z}}$ & \multicolumn{1}{c}{ Mean } & Minimum-Maximum \\
\hline 0.1 & $29( \pm 37)$ & $-38-90$ \\
1.0 & $86( \pm 8)$ & $55-100$ \\
10.0 & $92( \pm 7)$ & $61-100$ \\
\hline
\end{tabular}

y Percent inhibition of isolates after 7 days of growth in the dark at room temperature, determined by comparing treatments to growth in $5 \%$ carrot without mefenoxam, \pm standard error of mean (in parentheses) for each mefenoxam concentration. A negative value indicates that mycelial growth was greater than the nonamended control for some isolates.

${ }^{\mathrm{z}}$ Concentration of mefenoxam in 5\% carrot agar medium.

Table 5. Mean effective concentration to inhibit 50\% of hyphal growth $\left(\mathrm{EC}_{50}\right)$ for mefenoxam sensitivity of each mating type and race of Phytophthora nicotianae collected from North Carolina tobacco fields

\begin{tabular}{lrc}
\hline $\boldsymbol{P .}$ nicotianae & $\boldsymbol{N}$ & Mean $\mathbf{E C}_{\mathbf{5 0}}^{\mathbf{z}}$ \\
\hline Mating type & 32 & \\
A1 & 69 & $0.46 \mathrm{a}$ \\
A2 & 12 & $0.45 \mathrm{a}$ \\
A1/A2 & 4 & $0.41 \mathrm{ab}$ \\
A0 & & $0.009 \mathrm{~b}$ \\
Race & 28 & \\
Race 0 & 78 & $0.41 \mathrm{a}$ \\
Race 1 & 8 & $0.40 \mathrm{a}$ \\
Race 3 & 3 & $0.37 \mathrm{a}$ \\
Nonpathogenic & $0.64 \mathrm{a}$ \\
\hline
\end{tabular}

${ }^{\mathrm{z}}$ Means separation: mean $\mathrm{EC}_{50}$ values with the same letter do not differ significantly (Waller-Duncan $k=100$ ). 
region. Five haplotypes of $P$. nicotianae were identified, when heterozygous ITS sites were removed, in North Carolina based on concatenated sequences of the ITS, cox2, and nadh1 gene regions of 197 of the original 226 isolates (TreeBASE: Treebase.org, study citation 20632). Multiple haplotypes were found in counties in the coastal plains, piedmont, and mountains.

Of the five identified haplotypes, three were common (haplotype 1, haplotype 2, and haplotype 4), with haplotype 1 restricted to the burley and mountain region of North Carolina, and haplotypes 2 and 4 spread across the state in both flue-cured and burley tobacco fields (Fig. 1). Two haplotypes (haplotypes 3 and 5) were rare, with only one isolate collected for each, and both were collected in burley fields. Haplotype 3 was obtained from a field in Haywood County and haplotype 5 was obtained from a field in Buncombe County. Haplotype 3 was collected from a field with three total haplotypes and haplotype 5 was collected from a field with four total haplotypes. Eight fields had multiple haplotypes present: one field in the coastal plains, three in the piedmont, and four in the mountains. Haplotypes 2 and 4 were detected in the coastal plains field SAM-FAN (Sampson County) and in piedmont fields ALA-HER (Alamance County), SUR-JOH (Surry County), and YAD-BRO (Yadkin County). In the mountains, haplotypes $1,2,4$, and 5 were sampled from field

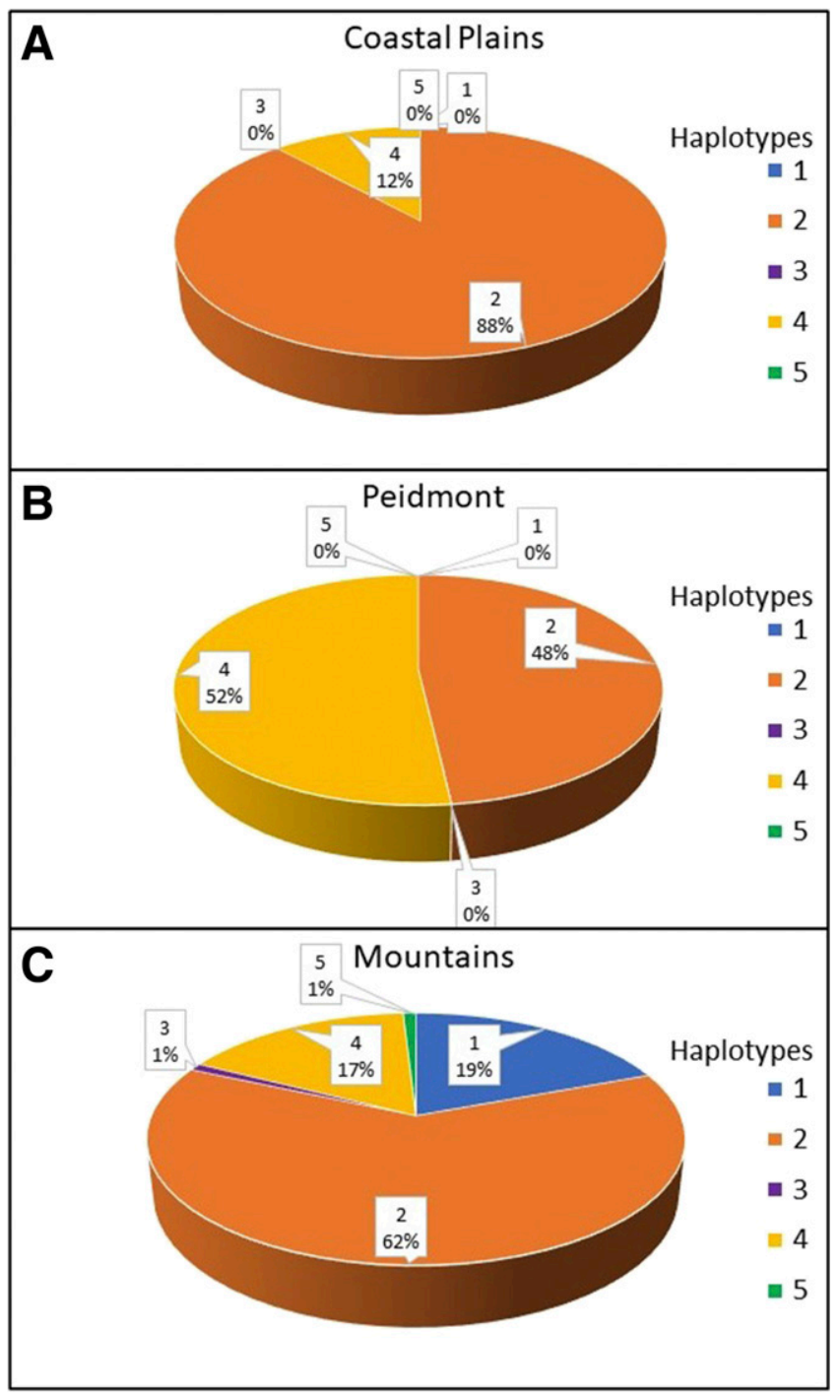

Fig. 1. Percentage of each detected Phytophthora nicotianae haplotype by tobaccogrowing region in North Carolina. Haplotypes were determined by single-nucleotide polymorphisms in sequences of the internal transcribed spacer, cox2, NADH dehydrogenase subunit $1, \beta$-tubulin, and translation elongation factor $1 \alpha$ gene regions. The percentage of each haplotype found in the coastal plains $(\mathbf{A})$, piedmont $(\mathbf{B})$, and mountains $(\mathbf{C})$ is shown below the haplotype name.
Buckner (Buncombe County); haplotypes 1, 2, and 3 were sampled from field Glance (Haywood County); haplotypes 1, 2, and 4 were sampled in field Hoyt (Haywood County); and haplotypes 1 and 2 were sampled from field Roberts (Madison County). Haplotypes were not correlated with race, mating type, or mefenoxam sensitivity.

\section{Discussion}

This study was conducted to determine the structure of the $P$. nicotianae population in North Carolina tobacco production regions and whether haplotypes were correlated to race, mating type, or sensitivity to the fungicide mefenoxam. In addition, we wanted to determine whether sexual reproduction in the field was possible where there was a mix of mating types. Collected isolates represented all previously reported races of $P$. nicotianae in North Carolina. Race 1 has remained the most prevalent race of $P$. nicotianae in North Carolina tobacco fields since the widespread deployment of single-gene resistance. Race 1 isolates composed $75 \%$ of all isolates recovered, which is similar to race distributions observed in Virginia (Parkunan et al. 2010). Despite the widespread use of single-gene resistance, $20 \%$ of isolates collected were race 0 . The proportion of race 1 and race 0 isolates was expected because of the fitness costs associated with race 1 isolates, which are generally less aggressive and have a reduced overwintering potential compared with race 0 isolates (Liu et al. 2016; Sullivan et al. 2005a,b). Race 1 isolates may be less aggressive than race 0 isolates due to decreased numbers of RxLR and crinkler effectors, which contribute to isolate pathogenicity (Liu et al. 2016). Due to these fitness penalties placed on race 1 , race 0 becomes the dominant race in the field if $P h p$-containing varieties are not planted.

In addition to all three races of the pathogen, representatives of both mating types were also collected during this study. In all, 14 fields from the burley area (mountains) and 19 fields from the fluecured area (piedmont and coastal plains) had populations with mixed mating types. Naturally occurring, mixed-mating-type populations have not been reported in this pathosystem. The only investigation of mating type in North Carolina tobacco areas was in 1959 (Apple 1959). Based on the small sample set in his study, only one mating type was thought to be present in the flue-cured region (A2) and the A1 mating type was thought to be geographically isolated in the mountainous burley region. Based on this information and other studies with $P$. nicotianae, populations of the pathogen in tobacco fields have been regarded as asexual, with zoospores exclusively driving the onset and spread of disease (Gallup et al. 2006).

Of the fields in the burley and flue-cured areas with a mixedmating-type population, 19 total fields had isolates that produced oospores when paired in culture. This is the first report of the potential for sexually compatible field populations of $P$. nicotianae. Oospores stained with tetrazolium bromide revealed a low to moderate (20 to $48 \%$ ) level of viable oospores from pairings. Currently, oospores for $P$. nicotianae have not been found in nature but are readily produced in culture. Despite moderate levels of viability, germination attempts to date have been unsuccessful. Similarly, 30 to $36 \%$ of oospores originating from hybrid alder Phytophthora spp. were viable, yet no germination attempts were successful (Delcán and Brasier 2001). Therefore, sexual reproduction in the field is possible but we still do not know its contribution to disease epidemics or genetic diversity in the pathogen population.

McDonald and Linde (2002) hypothesized that populations with mixed mating systems from sexual reproduction (oospores) and asexual reproduction (zoospores) pose the highest risk of evolution and ultimately overcoming selection pressures imposed by multiple management strategies. Based on these parameters, the asexual populations identified in North Carolina appear to pose some level of moderate risk. Based on this study, sexual reproduction could be contributing to genetic variability but variation arising through strictly asexual means also provides a genetic structure capable of quickly circumventing single-gene resistance in the host.

Sexual recombination gives the pathogen an evolutionary advantage, which can lead to quick shifts in the pathogen population to favor virulent isolates when single-gene resistance is deployed, or 
insensitive isolates when a single-mode-of-action fungicide is used repeatedly (Brasier 1992). In this study, all isolates of $P$. nicotianae were sensitive to mefenoxam, except isolate 59 from Sampson County, which had a reduced sensitivity to the fungicide. Isolate 59 was inhibited by only $36.6 \%$ with mefenoxam at $1 \mu \mathrm{g} / \mathrm{ml}$ but this is still sensitive to application rates of the fungicide. The overall mean $\mathrm{EC}_{50}$ was mefenoxam at $0.4 \mu \mathrm{g} / \mathrm{ml}$, similar to the previously reported $\mathrm{EC}_{50}$ of metalaxyl on $5 \% \mathrm{~V}-8$ agar at $0.4 \mu \mathrm{g} / \mathrm{ml}$ (Shew 1984). Even though most isolates were characterized as sensitive to mefenoxam, there is potential for insensitive isolates to become more prevalent (Hu et al. 2008; Shew 1985) and risk would likely be higher in fields where sexual reproduction is occurring. In our study, correlation between haplotypes and sensitivity to mefenoxam was not possible because all isolates had some sensitivity to the fungicide.

Of the original 581 isolates collected, a subset of 226 were selected for sequencing of the ITS, cox 2, nadh1, EF-1a, and $\beta$-tub gene regions. SNP were observed in the rDNA and mtDNA sequences and were used to distinguish five haplotypes. Haplotype 1 was limited to mountains of North Carolina, haplotype 2 and 4 could be found across the state in both burley and flue-cured tobacco-growing regions, and rare haplotypes 3 and 5 were represented by one isolate each and were found in the mountains. Haplotype did not correlate with race or mating type, which is similar to other populations of $P$. nicotianae in China, Spain, and across the world (Blaya et al. 2015; Mammella et al. 2013; Zhang et al. 2003).

In a study by Blaya et al. (2015), P. nicotianae isolates collected from pepper plants in Spain were genotyped using mtDNA gene regions. They found four haplotypes that did not correlate with phenotypic traits. Their study was much smaller and included only 16 isolates; thus, it seems that genetic variability based on mtDNA SNP was much lower for our North Carolina population because only five genotypes were detected out of 197 isolates (Blaya et al. 2015). In another population genetics study by Mammella et al. (2013), isolates of $P$. nicotianae from multiple countries and hosts were genotyped using four mtDNA and three nuclear DNA gene regions. They found 50 haplotypes out of 96 isolates. Unlike our North Carolina population, there were SNP in the nuclear DNA gene regions. Differences in number of haplotypes from the Mammella et al. (2013) study and ours may be due to different molecular markers because only the $\operatorname{cox} 2$ and $\beta-t u b$ gene regions were shared in both studies. In addition, isolates from the global $P$. nicotianae study were from multiple hosts, whereas our population of $P$. nicotianae was only collected from one species of tobacco from a single state. Though isolates from the global study did not group by geographic location, they did form a few large clades in a phylogenetic tree correlated with the host from which the isolate was taken (Mammella et al. 2013). In our study, a finer level of geographical grouping of North Carolina $P$. nicotianae haplotypes might emerge if another set of molecular markers, such as microsatellites, were used (Biasi et al. 2015, 2016).

Genetic variability in P. nicotianae is high despite reproducing primarily through asexual means. Many types of mechanisms contribute to genetic variability produced through asexual means, including mutations, genome instability, transposable elements, gene conversion, mitotic recombination, parasexual cycles, and supernumerary chromosomes (Kamoun 2003). Previous work identified very high levels of AFLP among asexual zoospore progeny (Gallup 2009). Using two AFLP markers, $100 \%$ of the loci were polymorphic, yielding a diversity index between 0.17013 and 0.44196 for each group of related asexual zoospore progeny. Asexual variation in single-zoospore isolates (SZI) from the same parental isolate has also been reported for $P$. infestans (Abu-El Samen et al. 2003) and P. sojae (Chen et al. 2009). For $P$. infestans, SZI from the same isolate can have differences in virulence than their parents and have detectable genetic variations. Using RAPD and AFLP, 32 SZI from a single parent grouped into 11 RAPD groups and 3 AFLP groups, indicating genetic variability among asexual progeny (Abu-El Samen et al. 2003). In $P$. sojae, differences in aggressiveness were detected in a population of SZI from the same parent (Chen et al. 2009). Such high levels of asexual variability increases the potential for a significant change, such as a change in race, mating type, aggressiveness, or fungicide sensitivity.

This study illustrated that genetic diversity can be detected within a pathogen population from a single host species with a few mitochondrial and nuclear gene region markers. Based on mitochondrial gene markers, there is some variability that can be linked to geographic location. Some haplotypes can be found across the state, while one is limited to burley tobacco production regions. However, race and mating type were not correlated to haplotypes with the selected markers in this study. In addition, tobacco fields with A1 and A2 isolates of $P$. nicotianae are able to produce viable oospores in vitro and sexual recombination may be contributing to genetic variability, although confirmation of sexual recombination in oospores is still needed. Many disease control practices effectively reduce the overall population numbers but place selection pressure on the pathogen population. This will lead to more genetic and phenotypic shifts in the population, which should be considered when deciding on future management strategies.

\section{Acknowledgments}

We thank A. Mendoza-Moran for her excellent technical assistance.

\section{Literature Cited}

Abu-El Samen, F. M., Secor, G. A., and Gudmestad, N. C. 2003. Genetic variation among asexual progeny of Phytophthora infestans detected with RAPD and AFLP markers. Plant Pathol. 52:314-325.

Apple, J. L. 1959. Sexuality of Phytophthora parasitica var. nicotianae. Phytopathology 49:37-43.

Biasi, A., Martin, F., Cacciola, S., San Lio, G., Grünwald, N., and Schena, L. 2016. Genetic analysis of Phytophthora nicotianae populations from different hosts using microsatellite markers. Phytopathology 106:1006-1014.

Biasi, A., Martin, F., and Schena, L. 2015. Identification and validation of polymorphic microsatellite loci for the analysis of Phytophthora nicotianae populations. J. Microbiol. Methods 110:61-67.

Bittner, R. J., and Mila, A. L. 2016. Effects of oxathiapiprolin on Phytophthora nicotianae, the causal agent of black shank of tobacco. Crop Prot. 81:57-64.

Blaya, J., Lacasa, C., Lacasa, A., Martinez, V., Santisima-Trinidad, A., Pascual, J. A., and Ros, M. 2015. Characterization of Phytophthora nicotianae isolates in southeast Spain and their detection and quantification through real-time TaqMan PCR. J. Sci. Agric. 95:1243-1251.

Brasier, C. M. 1992. Evolutionary Biology of Phytophthora Part 1: Genetic system, sexuality, and the generation of variation. Annu. Rev. Phytopathol. 30:153-171.

Brumfield, R. T., Beerli, P., Nickerson, D. A., and Edwards, S. V. 2003. The utility of single nucleotide polymorphisms in inferences of population history. Trends Ecol. Evol. 18:249-256.

Chaplin, J. F. 1962. Transfer of black shank resistance from Nicotiana plumbaginifolia to flue-cured N. tabacum. Tob. Sci. 6:184-189.

Chen, C.-Q., Huang, L.-L., Buchenauer, H., Zhao, H.-Y., Zuo, Y.-H., and Kang, Z.-S 2009. Diversity among single zoospore isolates derived from single-zoosporangia of Phytophthora sojae Kauf. and Gerd. J. Phytopathol. 157:181-187.

Chern, L. L., and Ko, W. H. 1994. Effects of high-temperature on physiological processes leading to sexual reproduction in Phytophthora parasitica. Mycologia 86:416-420.

Csinos, A. S., and Bertrand, P. F. 1994. Distribution of Phytophthora parasitica var. nicotianae races and their sensitivity to metalaxyl in Georgia. Plant Dis. 78:471-474.

Delcán, J., and Brasier, C. M. 2001. Oospore viability and variation in zoospore and hyphal tip derivatives of the hybrid alder Phytophthoras. For. Pathol. 31:65-83.

Gallup, C. A. 2009. The impacts of black shank resistance management on the population biology of Phytophthora nicotianae in tobacco. Online publication. North Carolina State University Institutional Dissertation Repository. http:// repository.lib.ncsu.edu/handle/1840.16/3128

Gallup, C. A., and Shew, H. D. 2010. Occurrence of race 3 of Phytophthora nicotianae in North Carolina, the causal agent of black shank of tobacco. Plant Dis. 94:557-562.

Gallup, C. A., Sullivan, M. J., and Shew, H. D. 2006. Black shank of tobacco. Plant Health Instruct. doi.org/10.1094/PHI-I-2006-0717-01

Grünwald, N. J., and Goss, E. M. 2011. Evolution and population genetics of exotic and re-emerging pathogens: Novel tools and approaches. Annu. Rev. Phytopathol. 49:249-267.

Hu, J. H., Hong, C. X., Stromberg, E. L., and Moorman, G. W. 2008. Mefenoxam sensitivity and fitness analysis of Phytophthora nicotianae isolates from nurseries in Virginia, USA. Plant Pathol. 57:728-736.

Hwang, J., and Benson, D. M. 2005. Identification, mefenoxam sensitivity, and compatibility type of Phytophthora spp. attacking floriculture crops in North Carolina. Plant Dis. 89:185-190.

Jee, H. J., and Ko, W. H. 1997. Stimulation of sexual reproduction in Phytophthora cactorum and $P$. parasitica by fatty acids and related compounds. Mycol. Res. 101:1140-1144. 
Jee, H. J., Tang, C. H., and Ko, W. H. 2002. Characterization of phytochemicals stimulatory to sexual reproduction in Phytophthora cactorum and P. parasitica. Bot. Bull. Acad. Sin. 43:203-210.

Johnson, E. S., Wolff, M. F., Wernsman, E. A., Atchley, W. R., and Shew, H. D. 2002. Origin of the black shank resistance gene, $P h$, in tobacco cultivar Coker 371-Gold. Plant Dis. 86:1080-1084.

Kamoun, S. 2003. Molecular genetics of pathogenic oomycetes. Eukaryot. Cell 2: 191-199.

Kannwischer, M. E., and Mitchell, D. J. 1978. The influence of a fungicide on the epidemiology of black shank of tobacco. Phytopathology 68:1760-1765.

Kroon, L. P., Bakker, F. T., van den Bosch, G. B., Bonants, P. J., and Flier, W. G. 2004. Phylogenetic analysis of Phytophthora species based on mitochondrial and nuclear DNA sequences. Fungal Genet. Biol. 41:766-782.

Lacourt, I., Panabières, F., Marais, A., Venard, P., and Ricci, P. 1994. Intraspecific polymorphism of Phytophthora parasitica revealed by analysis of mitochondrial DNA restriction fragment length polymorphism. Mycol. Res. 98:562-568.

Liu, H., Ma, X., Yu, H., Fang, D., Li, Y., Wang, X., Wang, W., Dong, Y., and Xiao, B. 2016. Genomes and virulence difference between two physiological races of Phytophthora nicotianae. Gigascience 5:1-8.

Lucas, G. B. 1975. Diseases of Tobacco, 3rd ed. Biological Consulting Associates, Raleigh, NC.

Mammella, M. A., Cacciola, S. O., Martin, F., and Schena, L. 2011. Genetic characterization of Phytophthora nicotianae by the analysis of polymorphic regions of mitochondrial DNA. Fungal Biol. 115:432-442.

Mammella, M. A., Martin, F. N., Cacciola, S. O., Coffey, M. D., Faedda, R., and Schena, L. 2013. Analyses of the population structure in a global collection of Phytophthora nicotianae isolates inferred from mitochondrial and nuclear DNA sequences. Phytopathology 103:610-622.

Martin, F. N., and Tooley, P. W. 2003. Phylogenetic relationships among Phytophthora species inferred from sequence analysis of mitochondrially encoded cytochrome oxidase I and II genes. Mycologia 95:269-284.

McDonald, B. A., and Linde, C. 2002. Pathogen population genetics, evolutionary potential, and durable resistance. Annu. Rev. Phytopathol. 40:349-379.

Mila, A., and Radcliff, J. 2015. Managing disease. Pages 116-144 in: Flue-Cured Tobacco Guide 2015. N. C. State Univ. Coop. Ext. Agric. Res. Bull. (Int. Comm. Northwest Atl. Fish.) 187 (revised)

Panabières, F., Ali, G. S., Allagui, M. B., Dalio, R. J. D., Gudmestad, N. C., Kuhn, M., Guha Roy, S., Schena, L., and Zampounis, A. 2016. Phytophthora nicotianae diseases worldwide: New knowledge of a long-recognised pathogen. Phytopathol Mediterr. 55:20-40.

Parkunan V., Johnson, C. S., Bowman, B. C., and Hong, C. X. 2010. Population structure, mating type, and mefenoxam sensitivity of Phytophthora nicotianae in Virginia tobacco fields. Plant Dis. 94:1361-1365.

Shew, H. D. 1983. Effects of soil matric potential on infection of tobacco by Phytophthora parasitica var. nicotianae. Phytopathology 73:1160-1163.

Shew, H. D. 1984. In vitro growth response of Phytophthora parasitica var. nicotianae isolates to metalaxyl. Plant Dis. 68:764-766.

Shew, H. D. 1985. Response of Phytophthora parasitica var. nicotianae to metalaxyl exposure. Plant Dis. 69:559-562.

Shew, H. D., and Lucas, G. B. 1991. Compendium of Tobacco Diseases. American Phytopathological Society, St. Paul, MN.

Sullivan, M. J., Melton, T. A., and Shew, H. D. 2005a. Fitness of races 0 and 1 of Phytophthora parasitica var. nicotianae. Plant Dis. 89:1220-1228.

Sullivan, M. J., Melton, T. A., and Shew, H. D. 2005b. Managing the race structure of Phytophthora parasitica var. nicotianae with cultivar rotation. Plant Dis. 89: 1285-1294.

Sullivan, M. J., Parks, E. J., Cubeta, M. A., Gallup, C. A., Melton, T. A., Moyer, J. W., and Shew, H. D. 2010. An assessment of the genetic diversity in a field population of Phytophthora nicotianae with a changing race structure. Plant Dis. 94:455-460.

Sutherland, E. D., and Cohen, S. D. 1983. Evaluation of tetrazolium bromide as a vital stain for fungal oospores. Phytopathology 73:1532-1535.

Tsao, P. H., Ugale, R., Hobbs, S., and Farih, A. 1980. Control of homothallic oospore formation in Phytophthora parasitica by culture manipulations. Trans. Br. Mycol. Soc. 75:153-156.

Valleau, W. D., Stokes, G. W., and Johnson, E. M. 1960. Nine years' experience with the Nicotiana longiflora factor for resistance to Phytophthora parasitica var. nicotianae in the control of black shank. Tob. Sci. 4:92-94

White, T. J., Bruns, T., Lee, S. B., and Taylor, J. 1990. Amplification and direct sequencing of fungal ribosomal RNA genes for phylogenetics. Pages 315-322 in: PCR Protocols: A Guide to Methods and Applications. Innis M A. D. H. Gelfand, J. J. Sninsky, and T. J. White, eds. Academic Press, San Diego, CA

Zhang, X. G., Sun, W. X., Guo, L., Yu, J. F., and Chang, C. J. 2003. Genetic and pathogenic variation among tobacco black shank strains of Phytophthora parasitica var. nicotianae from the main tobacco growing in China. J. Phytopathol. 151: 259-266. 